\title{
The impact of drive mode of a hybrid drive system on the energy flow indicators in the RDE test
}

The drive to reduce fuel consumption of vehicles equipped with internal combustion engines leads to an increasing share of hybrid drives used in various means of transport. Such hybrid vehicles, thanks to the use of diesel-electric drive systems, allow for a fuel consumption reduction, and thus to reduce the carbon dioxide emissions. This fuel consumption reduction results from a specifically selected energy flow strategy in hybrid systems. This strategy was the focus of the research performed in order to identify the energy flow conditions in a hybrid drive system in driving conditions corresponding to the RDE test. A Lexus LS 500h vehicle was tested in two drive modes, while determining the related energy flow conditions, including the operating conditions of: electric motors, internal combustion engine and battery. Energy balance was determined taking into account the high voltage battery discharge and charging energy as well as the energy recovered during regenerative braking. It was found that in the RDE test conditions the vehicle is in electric mode for over $30 \%$ of the distance and $35 \%$ of the drive time, with the energy balance of the vehicle being positive (SOC $C_{\text {end }}>S O C_{\text {start }}$ ). Additionally, it was pointed out that the time spent in the electric mode when driving in urban conditions is about 50\% and decreases to about $15 \%$ for highway conditions.

Keywords: hybrid electric vehicles, energy management, electric range, real driving conditions, real driving emissions test

\section{Introduction}

The automotive industry has been intensively modernized in recent years in the aspect of exhaust emissions reduction. Modern passenger vehicles must comply with emission norms in real driving conditions and extended environmental conditions relative to the pre-existing dynamometer tests (variable ambient temperature, pressure, congestion, driving style etc.) [12]. RDE road tests should therefore take into account all possible road situations while maintaining a set specific driving style, so that the obtained emission results are indicative of the vehicle technical characteristics [1]. Thus, there is a number of conditions that must be met in order to perform these test [3].

Vehicle manufacturers continuously introduce modern drive systems in order to meet the stringent emission norms. Despite the increase in the electric vehicles market share, the internal combustion engine continues to be the main propulsion mechanism used in vehicle drive systems (Fig. 1). Their presence will be noticeable in all kinds of hybrid drives $[8,13]$.

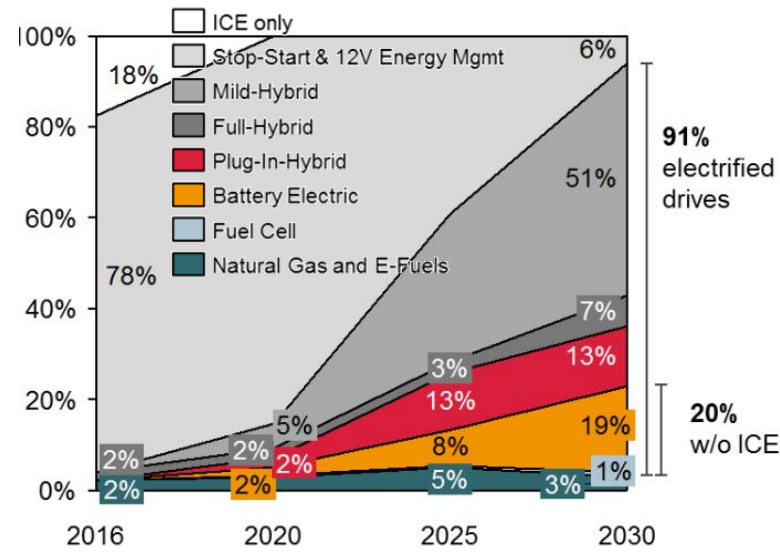

Fig. 1. Market forecast on drivetrain topologies for Europe from 2016 to 2030 (registration of new passenger cars) [13]
The share of vehicles with exclusively electric drives is estimated at $20 \%$, while the market share of vehicles using fuel cell technology and alternative fuels is miniscule.

In the light of the information presented, it is important to conduct research of hybrid vehicles energy balance assessment, as they have the largest market share.

\section{Aim of research}

The energy flow method in a hybrid drive system depends on the hybrid drive solution (mild hybrid, full hybrid) and on its operating conditions (SOC, battery capacity and others). The article authors attempted to determine the impact of driving mode settings (ECO and SPORT) in a vehicle with a full hybrid drive system on its energy flow indicators. To achieve this, drives were made in real conditions in accordance with the RDE test requirements. The following were performed:

- The share of hybrid and electric drive use in each phase of the drive cycle separated for different drive modes was determined.

- Analyses of energy flow in the vehicle drive from the perspective of energy recovery and generation in the vehicle.

- Energy flow indicators were determined and quantified.

\section{Research object}

Measurements of the energy flow were performed on a Lexus LS 500h with a hybrid drive system, equipped with a spark-ignition internal combustion engine with basic technical parameters as listed in Table 1.

The Lexus LS 500h is equipped with the same drive system that was introduced to the market in 2017 in the Lexus LC 500h [6]. This was the first time such a hybrid drive, so-called Multi Stage Hybrid System - MSHS was used in it. This solution is characterized by the addition of a four-speed hydrokinetic transmission (Multi Stage Shift Device - MSSD) between the planetary gear and the power 
split device [11]. New drive system components introduced in this vehicle have been compared to previous generations of drive systems in Fig. 2.

Table 1. Test vehicle technical data [14]

\begin{tabular}{|c|c|}
\hline \multicolumn{2}{|c|}{ Combustion engine } \\
\hline Engine type & $\begin{array}{l}\text { 8GR-FXS, } \\
\text { V6/24-valve }\end{array}$ \\
\hline Displacement $\left[\mathrm{cm}^{3}\right]$ & 3456 \\
\hline Bore $\times$ stroke $[\mathrm{mm}]$ & $94 \times 83$ \\
\hline Compression ratio [-] & $13: 1$ \\
\hline Fuel injection system & electrical fuel injection, D-4S \\
\hline Max power $[\mathrm{kW}]$ at speed $[\mathrm{rpm}]$ & $220 / 6600$ \\
\hline Max torque $[\mathrm{Nm}]$ at speed $[\mathrm{rpm}]$ & $360 / 5100$ \\
\hline Emission standard & Euro 6 \\
\hline \multicolumn{2}{|c|}{ Electric front motor (MG2) } \\
\hline Max power $[\mathrm{kW}]$ & 132 \\
\hline Max torque $[\mathrm{Nm}]$ & 300 \\
\hline \multicolumn{2}{|c|}{ Battery system } \\
\hline Type of battery & Li-Ion (3.7 V/cell) \\
\hline Cell quantity [-] & $2 \times 42$ cells \\
\hline Battery power $[\mathrm{kW}]$ & 44 \\
\hline Battery capacity [Ah] & 3.6 \\
\hline Energy [kWh] & 1.1 \\
\hline Battery voltage [V] & 310.8 \\
\hline \multicolumn{2}{|c|}{ Hybrid drive system } \\
\hline Hybrid drive system & $\begin{array}{l}\text { 10-speed, Lexus Multi Stage } \\
\text { Hybrid }\end{array}$ \\
\hline $\begin{array}{l}\text { Total power of the hybrid drive } \\
\text { system }[\mathrm{kW}]\end{array}$ & 264 \\
\hline Top vehicle speed $[\mathrm{km} / \mathrm{h}]$ & 250 \\
\hline $\mathrm{CO}_{2}$ emission combined $[\mathrm{g} / \mathrm{km}]$ & 141 \\
\hline
\end{tabular}

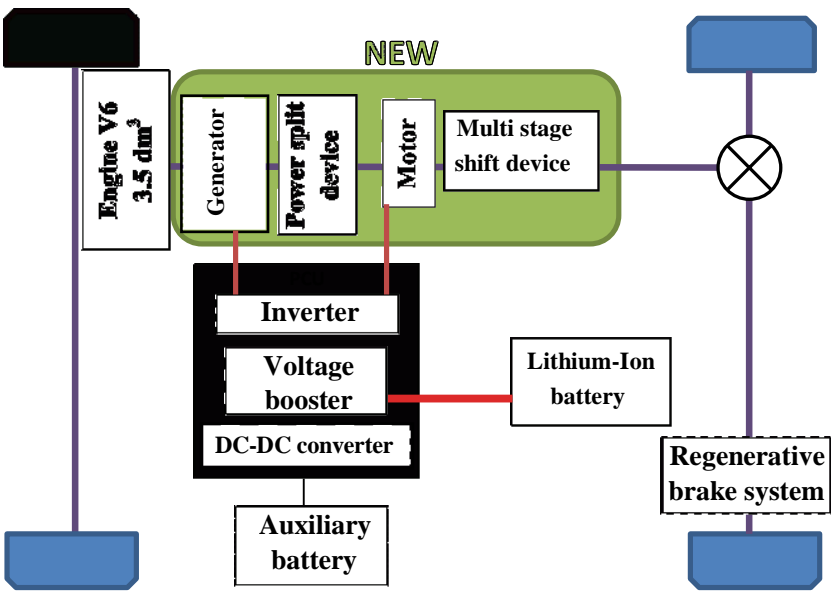

Fig. 2. Multi-Stage Hybrid System configuration [7]

The additional system (MSSD) enables manual gear change to shape the vehicle drive dynamics. The additional transmission consists of four gears, and it enables simulating ten transmission ratios in the drive system operation
(Fig. 3a). The last ratio is dedicated for lower engine rotational speeds [7].

The previous drive system version was equipped with a two-stage transmission coupled with an electric motor (Fig. 3b) with two transmission ratios 1.9 and 2.9 [10]. The current solution of the MSSD system, located at the output connection of the vehicle drive system (Fig. 3b), has four gear ratios $(3.538,1.888,1.000,0.650)$ [5]. The driver can choose the driving mode to be either the ten transmission ratios simulation system, the classic planetary gear system or the electric mode.

The use of MSSD transmission, compared to the two-mode solution from the previous generation, allows the transmission of up to 3.5-times higher output torque to the wheels than the old solution, with the torque share of the internal combustion engine significantly increased (Fig. 3b) [4].

a)

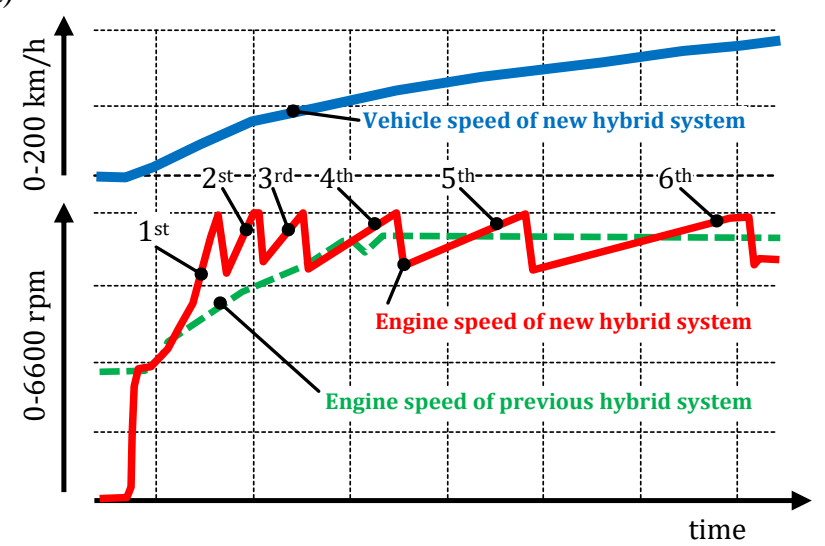

b)

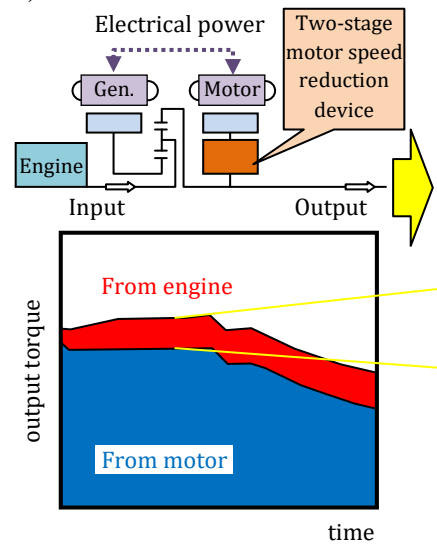

Previous hybrid system

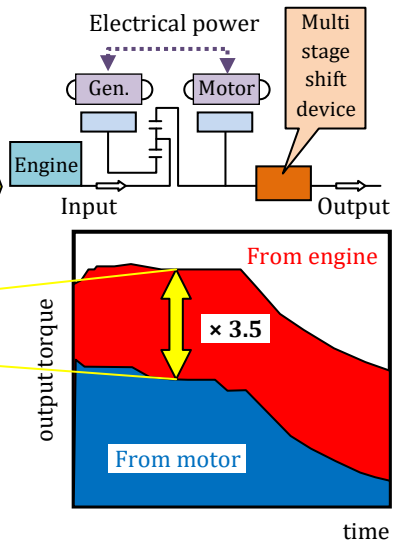

New hybrid system
Fig. 3. Development of Multi Stage Hybrid System: a) wide-open throttle acceleration, b) improvement of output torque [4]

\section{Research methodology}

The tests were performed using software dedicated to Toyota vehicles, that registered selected parameters via the OBD connector. The signal came from sensors in the drive system. The most important ones are: an inductive crankshaft speed sensor mounted on a gear wheel, speed and torque sensors for electrical machines, an accelerator pedal position sensor and an active vehicle speed sensor. The onboard diagnostic system allowed recording data from the hybrid drive system monitor was used to obtain vehicle 
motion parameters and hybrid drive operating conditions. During the tests the following values were recorded: vehicle speed (v), combustion engine speed (n), battery charge status (SOC), speed and torque of electric motors and current flow to or from the battery (IB). The diagram of the performed tests is shown in Fig. 4. In addition, an independent system recorded the geographical position of the vehicle to determine the route.

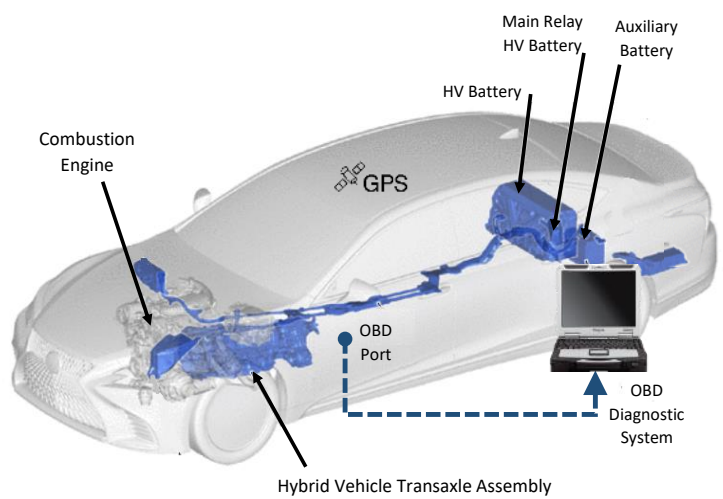

Fig. 4. A scheme of Lexus Hybrid Drive System along with the applied measuring devices (based on [14])

The test drive was conducted in the Poznan agglomeration and its surroundings in real driving conditions on a work day. Traffic congestion occurred during the drive (meaning traffic intensity greater than the capacity of a given road). The route was about $77 \mathrm{~km}$ long and the total test drive duration was about 110 minutes. The route included fragments of urban, rural and highway traffic (Fig. 5). Basic parameters of the performed tests are described in Table 2.

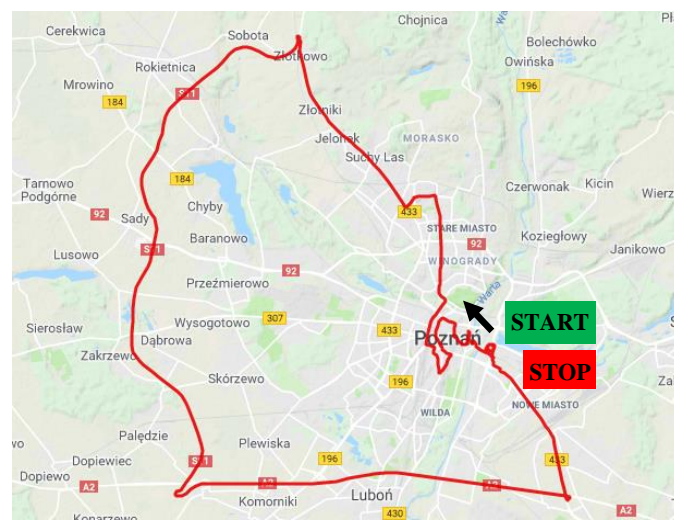

Fig. 5. Map of the road tests route

Table 2. Test conditions for hybrid drive in two driving modes

\begin{tabular}{|l|c|c|}
\hline Mode & ECO & SPORT \\
\hline Test duration $[\mathrm{s}]$ & 6547 & 6440 \\
\hline Test route length $[\mathrm{km}]$ & 76.86 & 76.85 \\
\hline SOC (initial/final) & $44.31 / 57.25$ & $40.78 / 55.29$ \\
\hline
\end{tabular}

The energy flow in the drive system during battery discharging, charging and recuperative braking was also calculated based on:
- energy flow:

$$
\Delta \mathrm{E}=\int_{\mathrm{t}=0}^{\mathrm{t}=\mathrm{t}_{\max }} \mathrm{U} \cdot \mathrm{I} \mathrm{dt}
$$

The instantaneous values of energy flow $\Delta \mathrm{E}_{\mathrm{i}}$ are divided according to the following criteria:

- discharging:

$$
\Delta \mathrm{E}_{\text {dis }}=\int_{\mathrm{t}=0}^{\mathrm{t}=\mathrm{t}_{\max }} \mathrm{U} \cdot \operatorname{Idt}\left(\text { if } \Delta \mathrm{E}_{\mathrm{i}}<0\right)
$$

- charging:

$$
\Delta \mathrm{E}_{\mathrm{ch}}=\int_{\mathrm{t}=0}^{\mathrm{t}=\mathrm{t}_{\max }} \mathrm{U} \cdot \mathrm{Idt}\left(\text { if } \Delta \mathrm{E}_{\mathrm{i}}>0 \text { and } \mathrm{M}_{\mathrm{reg}} \geq 0\right. \text { ) }
$$

- recuperative braking:

$$
\Delta \mathrm{E}_{\text {reg }}=\int_{\mathrm{t}=0}^{\mathrm{t}=\mathrm{t}_{\max }} \mathrm{U} \cdot \mathrm{Idt}\left(\text { if } \Delta \mathrm{E}>0 \text { and } \mathrm{M}_{\text {reg }}<0\right)
$$

where: $\mathrm{U}$ - voltage [V], I - current [A], t - time [h], $\mathrm{M}_{\text {reg }}-$ braking torque $[\mathrm{Nm}]$.

The tests were performed in two selected vehicle modes, i.e. ECO and SPORT. In order to determine the electric mode share in the entire test drive, sections of the route characterized by specific parameters were determined (equation (1)-(4)). Based on this separation, the modes of the hybrid drive system operation were determined: driving, acceleration and braking during operation of the hybrid drive (HEV), vehicle stop, driving, acceleration and braking without the accompanying work of the internal combustion engine, i.e. system operation in electric mode (EV). The adopted criteria are included in Table 3.

Table 3. Criteria for determining individual modes during the test

\begin{tabular}{|l|l|}
\hline Mode & Parameters \\
\hline HV drive & $\mathrm{a}=0 \wedge \mathrm{n}>600 \wedge \mathrm{v}>0$ \\
\hline EV drive & $\mathrm{a}=0 \wedge \mathrm{n}<600 \wedge \mathrm{v}>0$ \\
\hline HV acceleration & $\mathrm{a}>0 \wedge \mathrm{n}>600 \wedge \mathrm{v}>0$ \\
\hline EV acceleration & $\mathrm{a}>0 \wedge \mathrm{n}<600 \wedge \mathrm{v}>0$ \\
\hline vehicle stop & $\mathrm{v}=0$ \\
\hline braking & $\mathrm{a}<0 \wedge \mathrm{v}>0 \wedge \mathrm{n}>600$ \\
\hline EV braking & $\mathrm{a}<0 \wedge \mathrm{v}>0 \wedge \mathrm{IB}>0 \wedge \mathrm{n}<600$ \\
\hline
\end{tabular}

\section{Results analysis}

\subsection{RDE test drive conditions}

Table 3 was used to determine the percentage shares of drive modes of the hybrid drive system in the test. The results were presented in relation to both the test duration and the test route length. These results are shown in Fig. 6 and Fig. 7.
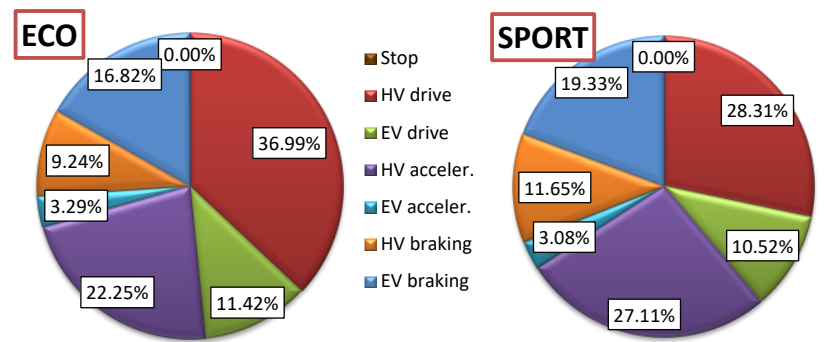

Fig. 6. The percentage share of individual driving modes in relation to distance traveled during the test 


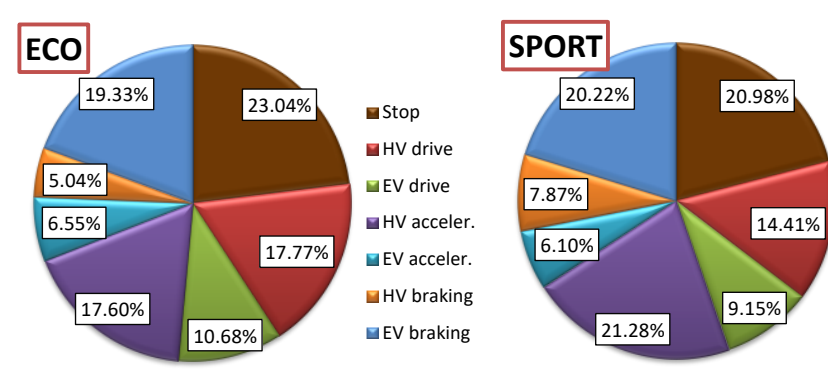

Fig. 7. The percentage share of individual driving modes in relation to the total test travel time

Hybrid mode drive had the largest share of operating time for the ECO test route $(36.99 \%)$, and the smallest share was obtained for accelerating in electric mode (about $3 \%$ ). In SPORT mode, the largest share also appears for driving in hybrid mode $(28.31 \%)$. The biggest difference between the ECO and SPORT test drives is for this very driving mode $(8.68 \%)$. In relation to the test duration (not including the vehicle's stops), the largest percentage share in the test drive using ECO mode is attributed to braking in electric mode (19.33\%). A similar situation (although not for the largest share) occurs in the SPORT drive mode. In this case, the share of braking in the EV mode is over $20 \%$. It follows that braking the vehicle in most cases takes place with the combustion engine switched off.

Similar shares regardless of the vehicle driving mode (ECO or SPORT) occur for electric driving (about 10\%) and for acceleration in these modes (about 6\% in each). It can be concluded that the change of drive mode does not change share of using the electric driving mode significantly.

The hybrid drive system operating conditions during the tests are shown in Fig. 8. The test was divided into individual drive modes. An electric and hybrid mode as well as parking have been separated and colored individually. They were marked with the background colors as: green, red and yellow respectively.
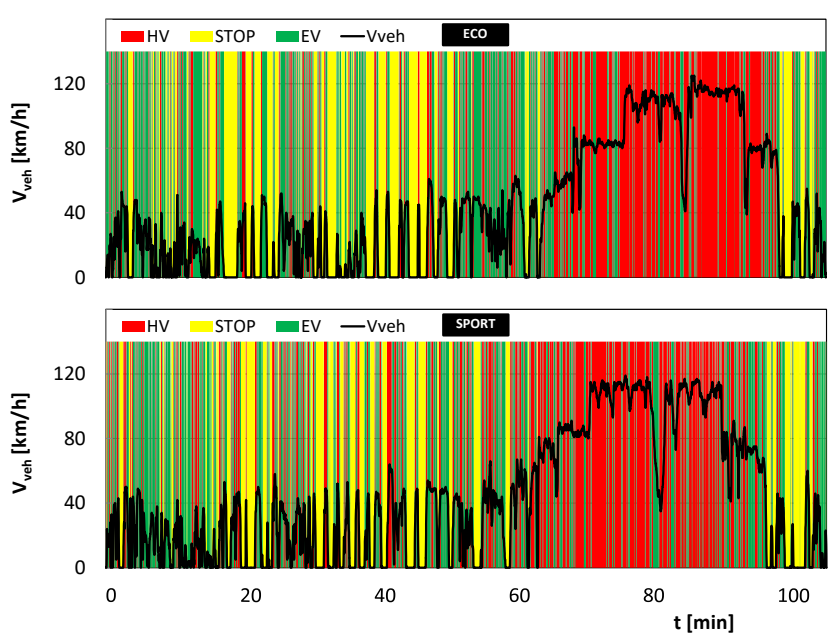

Fig. 8. The performed tests characteristics with a distinction between operation in hybrid and electric modes as well as vehicle stop

The characteristic operation of the drive system in hybrid mode for the highest test drive speeds can easily be seen when analyzing the data from Fig. 8. However, at low driving speeds, typical of urban areas, a definite majority share of the electric mode and vehicle stops is observed (depending on the conditions present on the road).

\subsection{Energy flow in an RDE test}

The research also addressed the subject of type approval test - RDE (Real Driving Emissions). In accordance with the speed requirements for this test, the drive cycles were divided into three sections: urban (red), rural (yellow) and highway (green). Instantaneous energy changes were calculated using equation (1), cumulative values were then calculated. The results of these calculations are presented in Fig. 9.

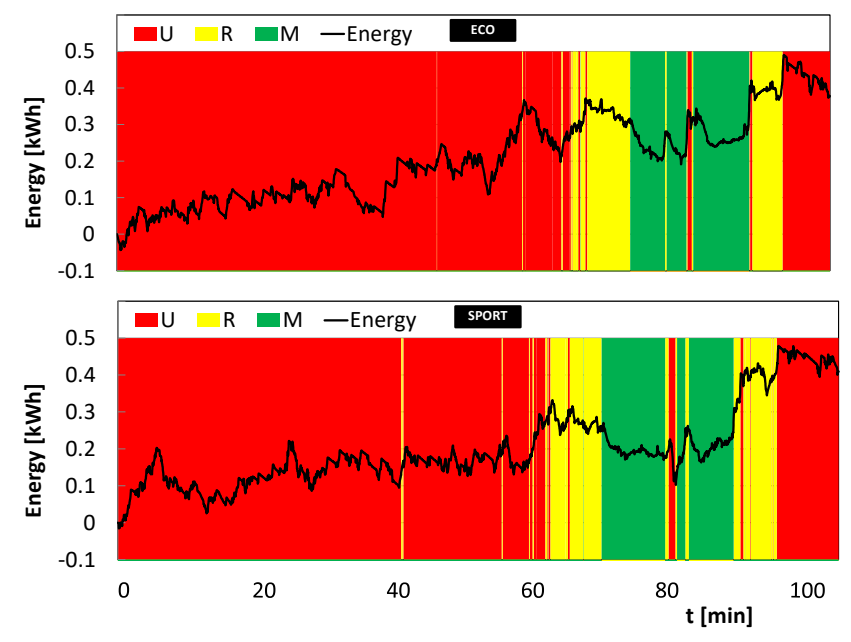

Fig. 9. Energy change during the RDE test by section (urban, rural, highway)

Analysis of Fig. 9 shows that the overall energy flow is positive. The final value for the ECO test is $0.38 \mathrm{kWh}$, and for the SPORT test $0.40 \mathrm{kWh}$. The boundaries between test drive sections are also very clear. They occur in the following order: urban, rural, highway, rural and then urban again (with small interruptions in the sections continuity).

Using equations (2)-(4), the test drives were classified according to the type of energy lost/recovered. The charging, discharging of the battery and the so-called recuperation, i.e. energy recovery from braking, both in EV ( $\mathrm{n}<600$ $\mathrm{rpm})$ and HV ( $>600 \mathrm{rpm})$ modes - Fig. 10.

Analyzing the data in Fig. 10, some characteristic test sections can be seen. At higher travel speeds, the battery is more often recharged from the combustion engine (prevalence of blue background). Thus the overall energy flow decreases. Both drives exhibit the same relationship. At lower speeds (urban and rural sections) the type of energy flow through the hybrid drive system changes with a high frequency. The drive system is designed to quickly replenish the battery charge level, which has dropped, for example as a result of driving in electric mode or assisting the internal combustion engine with electricity.

The energy flow analysis was performed for each section of the drive test (Fig. 11) as well as for the entire test broken down by the vehicle's operating mode (Fig. 12). Urban driving conditions constitute approximately $70-75 \%$ of energy discharged (in both driving modes). However, energy recovery in urban traffic conditions provided ap- 
proximately $70 \%$ of the total energy recovered in the test drive. In the two remaining sections, about $15 \%$ of energy is recovered for each. So due to the frequent vehicle speed changes, the charging energy in the urban section provides about $70 \%$ of the total charging energy (regardless of the driving mode). Due to the specificity of the SPORT mode, battery charging is much more common than in the ECO mode in the urban and highway phase (Fig. 11a).

a)

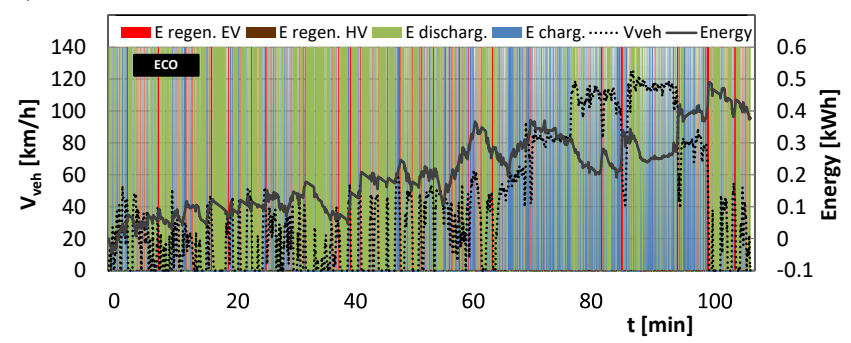

b)

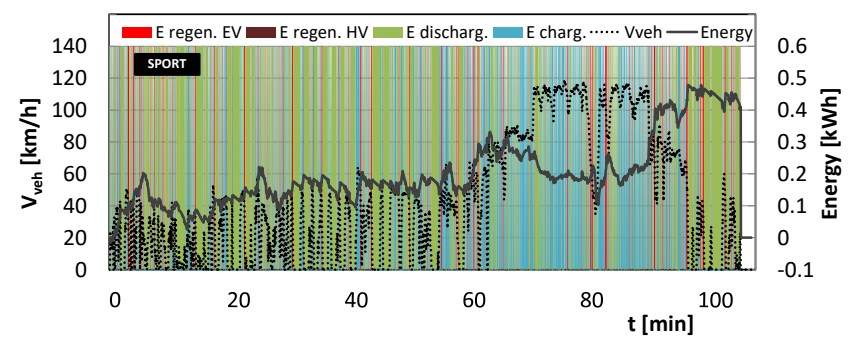

Fig. 10. Energy flow with flow conditions determined using equations (1) - (5) with the background showing the vehicle travel speed: a) in ECO mode, b) in SPORT mode

a)

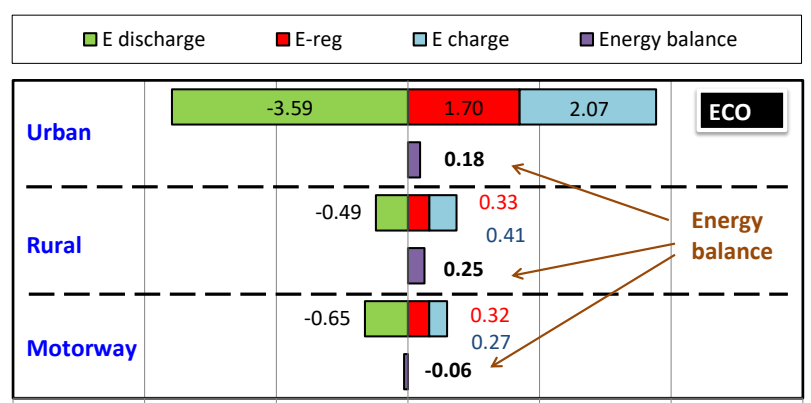

b)

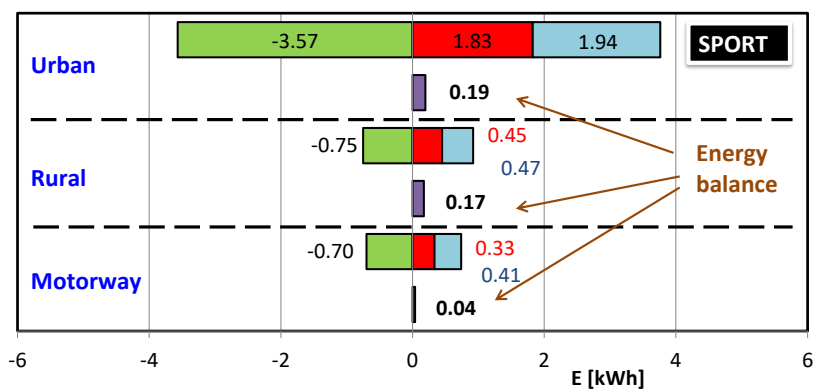

Fig. 11. Energy flow in the hybrid drive system divided into RDE test modes: a) ECO, b) SPORT

Analysis of the total energy flow balance indicates their large similarities for the tested drive modes (Fig. 12). Differences amount to about $5 \%$ for the analysis of individual energy balance components. The differences obtained may also result from different initial state of charge of the battery. In ECO mode the SOC was $44 \%$, while in sport mode it was $40 \%$.

a)

$\square$ Regeneration $\square$ Discharge $\square$ Charge $\square$ Change

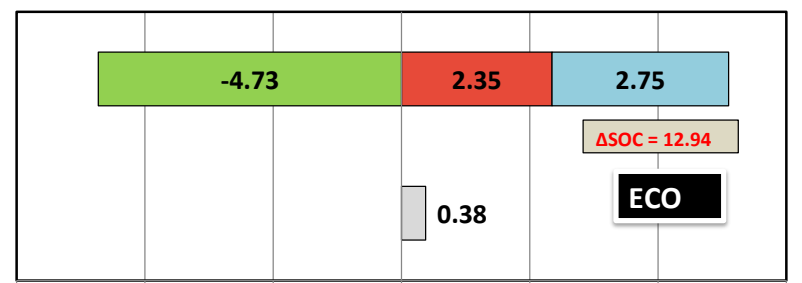

b)

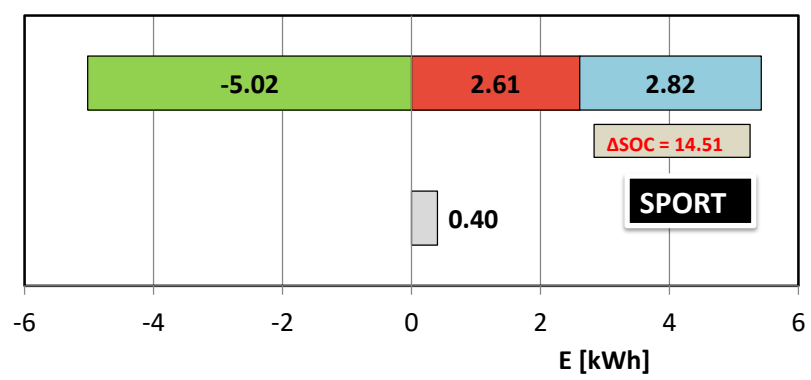

Fig. 12 Total energy flow recorded in a hybrid drive system in the two driving modes: a) ECO, b) SPORT

\subsection{Electric motors operating conditions and voltage amplification}

The similarity of the drive cycles in two driving modes (Fig. 8) should result in similar operating conditions for the electric motors. The characteristics of the MG1 engine (mainly operating as a generator) are shown below. Positive torque (irrespective of the rotation direction) indicates engine operation with MG2 motor assist. The scope of this work is small and amounts to only a few percent of the total time and work output (Fig. 13 - MG2 assist). This motor's contribution to energy generation is much greater. Values of generated torque (approximately $100 \mathrm{Nm}$ ) at positive rotational speeds indicate that this generator works much more frequently when the internal combustion engine is running. The principle of the planetary gear operation and the way in which the internal combustion engine and electric motors/generators in Lexus/Toyota vehicles are connected indicates that the negative speeds of the generator are obtained primarily when the internal combustion engine is switched off $[2,9]$. Such conditions cause the generated torque values to be much smaller and amount to about 50 $70 \mathrm{Nm}$ (these values are similar to each other in both driving modes - Fig. 13 a and b).

The MG2 motor has higher power and torque output than the MG1 motor, and is connected in parallel with the internal combustion engine. Due to such a solution it can be used, for example, to increase the output power of the drive system. In the "drive" setting (positive speed and torque), this motor supports the internal combustion engine or drives the vehicle wheels by itself (Fig. 14). Voltage in the range $300-400 \mathrm{~V}$ is used in a considerable range of work 
a)

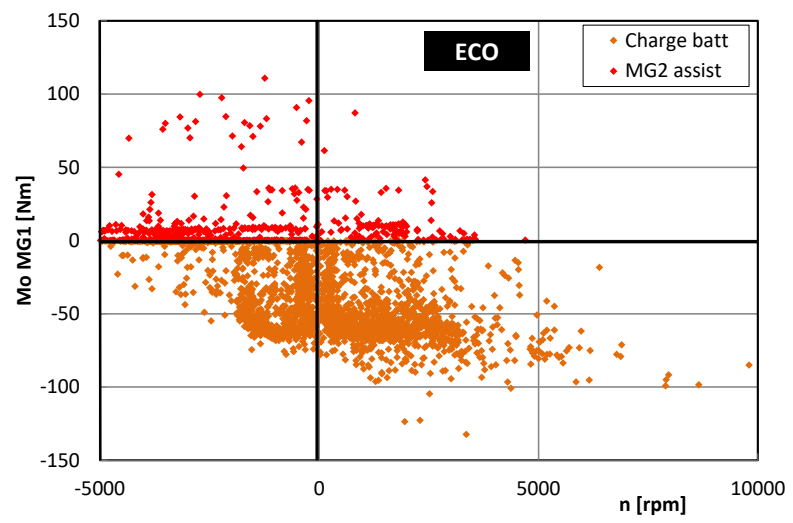

b)

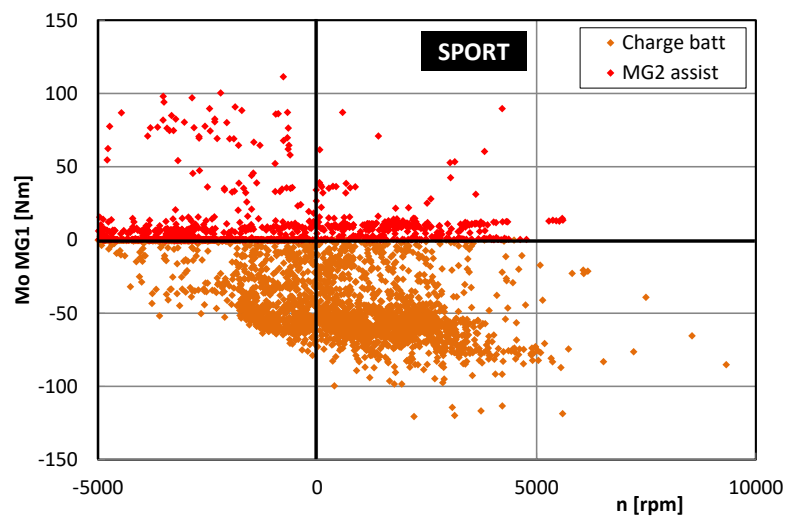

Fig. 13. Operating conditions of the MG1 electric motor in two driving modes: a) ECO, b) SPORT

a)

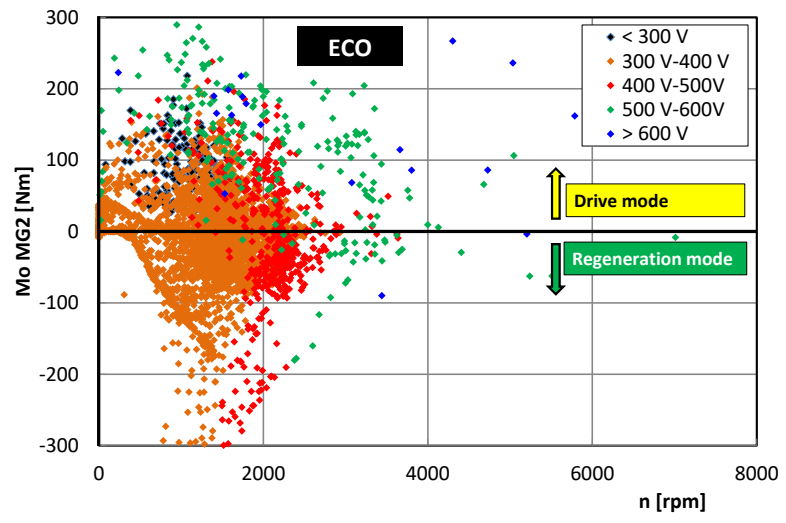

b)

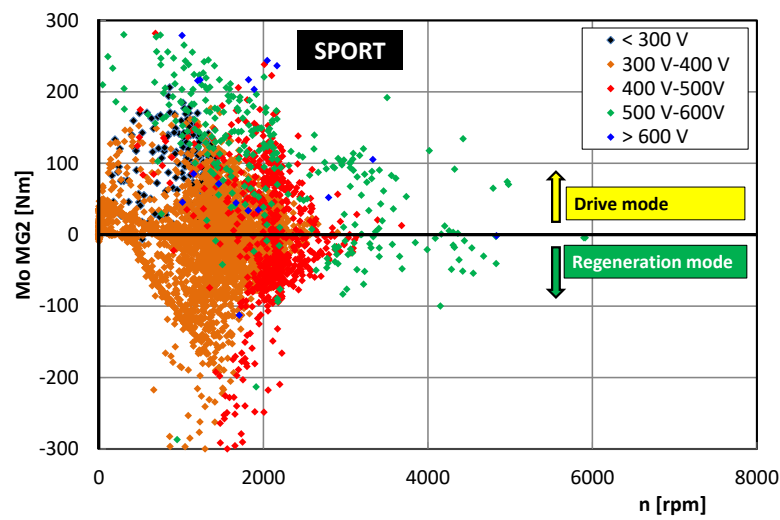

Fig. 14. Operating conditions of the MG2 motor depending on the inverter voltage and vehicle driving mode: a) ECO, b) SPORT output. Large voltage values are used only in several areas of work (maximum torque values regardless of the rotational speed). This situation is similar in both drive cycles: using ECO and SPORT modes. Energy recovery in the generator (MG1) takes place using electricity in the 300 $500 \mathrm{~V}$ range (scale including negative torque values). Larger voltage values relate to higher generator rotational speeds. The work area during regenerative braking is significantly reduced in relation to the area covered by a working internal combustion engine. Energy recovery does not take place at low rotational speeds. In the low speed range, a hydraulic brake system is used to apply the load.

The use of different converter voltage values was analyzed in the test drive cycle conditions (Fig. 15). It was found that 300-400 V are the most commonly used values. System operation with larger values is obtained during rapid changes in the vehicle speed. This applies mainly to acceleration or braking. The results shown in Fig. 15 correspond to those in Fig. 14, since high voltage values are more often related to internal combustion engine operation than generator mode (regenerative braking). It means that these inverter operating conditions relate to the possibility of obtaining a high value of torque and power in the MG2 motor.

a)

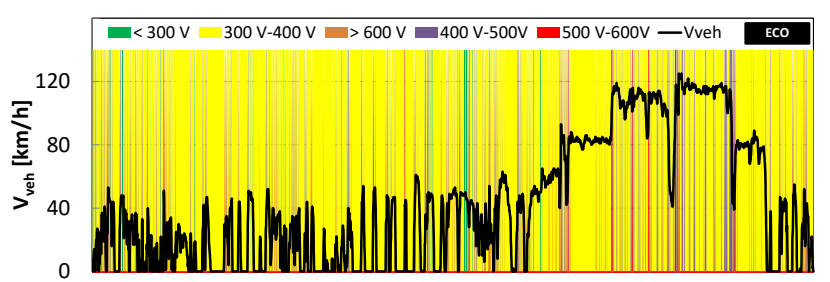

b)

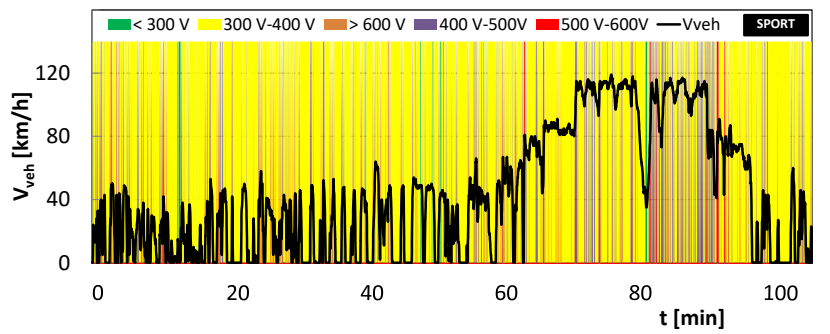

Fig. 15. The inverter voltage values in the RDE drive test in two vehicle modes: a) ECO, b) SPORT

Full analysis of the above results indicates that the voltage value in the $300-400 \mathrm{~V}$ range occurs $80 \%$ of the time (Fig. 16). These values are similar in both driving modes.

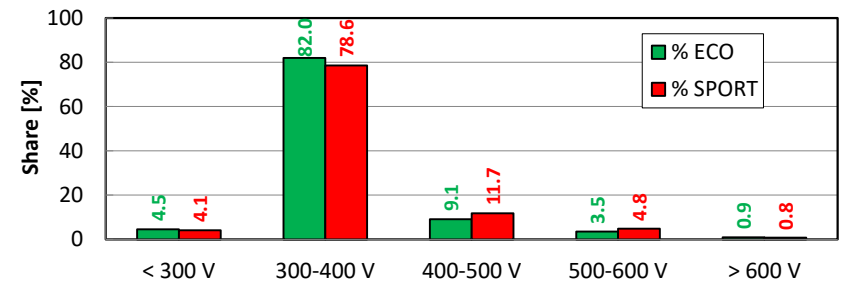

Fig. 16. Percentage shares of inverter voltage ranges in the RDE test conditions for the two driving modes 
Due to the higher acceleration and deceleration values in sport mode, voltage values above the $400 \mathrm{~V}$ range can be observed more often. Increasing the share of these ranges resulted in a few-percent reduction in the voltage being in ranges below $400 \mathrm{~V}$.

\subsection{Electric mode use}

The large operation time share of the electric drive in the real driving conditions of a vehicle with a hybrid drive system is the main focus of work related to the optimization of power and energy flow in hybrid drive systems. Hence, based on the test drive cycles, the conditions conducive to using the electric mode were determined and broken down into: constant vehicle speed, acceleration and braking (Fig. 17). Acceleration of a vehicle weighing over $2000 \mathrm{~kg}$ [14] has been found to require the operation of an internal combustion engine (or the use of hybrid drive mode). The acceleration time share when driving on only the electric motors is small, regardless of which drive mode is used, ECO or SPORT.
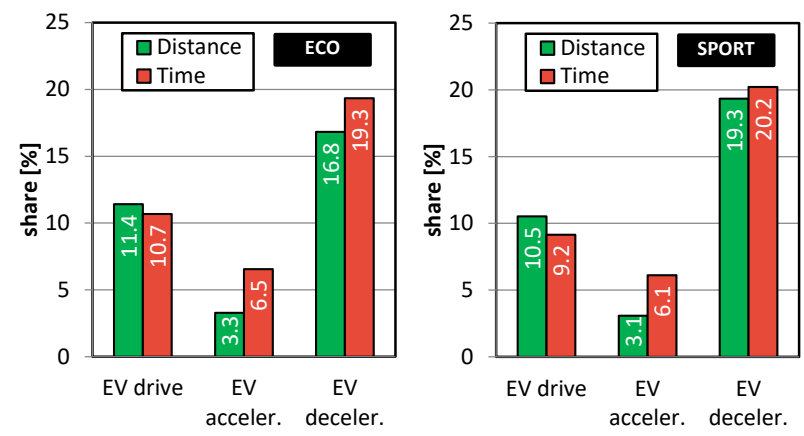

Fig. 17. The share of electric drive mode use relative to time and distance travelled with a hybrid drive system in two driving modes

The collective analysis of the vehicle's electric mode use indicates that this "emission-free" driving mode is used in only about $35 \%$ of the travel time (Fig. 18). In [2] the authors concluded, based on their research results, that the average electric mode driving share ranges from $30-60 \%$ in urban driving conditions, with a range of different battery charge values (higher values of the EV mode share correlate with a large initial SOC value). In the performed studies these results have been confirmed, with the initial SOC being around $40 \%$.

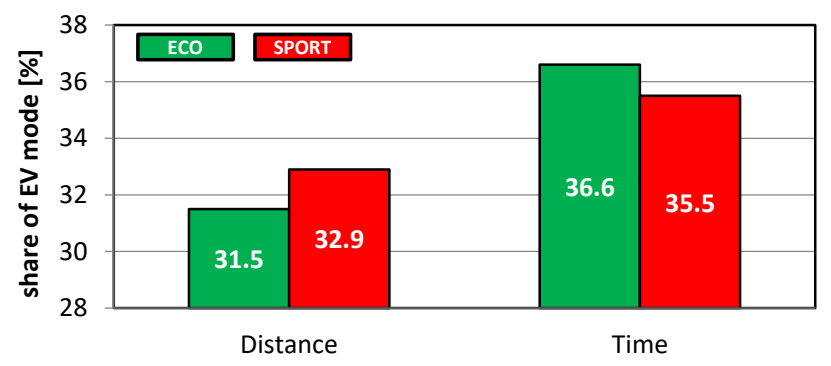

Fig. 18. Vehicle's operating time share in electric mode relative to the time and distance traveled

Analysis of the EV mode operating intervals depending on the driving conditions (urban, rural, highway) indicates the existence of a relationship between these quantities (Fig. 19). With the increase of the mean drive speed, the proportion of EV mode decreases rapidly. The share of EV operating mode is mostly influenced by the limited number of vehicle deceleration and braking actions (lack of energy recovery) as well as the hybrid system's operation strategy defining the battery state of charge. It would be possible to increase the EV mode share in the rural and highway driving conditions, but it would result in a significant reduction of the SOC value towards the end of the driving test. Such a strategy is not used due to the lack of a plug-in installation on the tested vehicle, which necessitates the use of strategies that lead to relatively small SOC changes while driving.

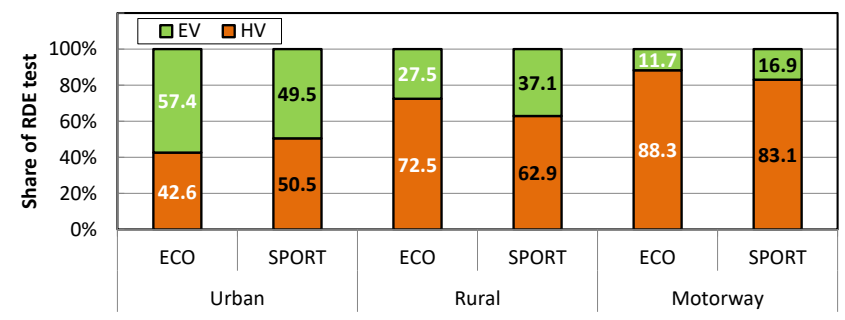

Fig. 19. The share of hybrid and electric mode in urban, rural and highway conditions in relation to the distance of the vehicle test drive

\section{Conclusions}

From the performed tests and analyzes, it was found that the use of the SPORT mode compared to the ECO mode results in:

- increased share of hybrid drive use during acceleration, which was caused by the forced operation of two drive sources in the hybrid drive system,

- no significant differences in the energy balance analysis results: similar values (with up to $5 \%$ error) for charging and discharging energy were obtained, as well as for energy recovery,

- no significant differences in the shares of individual driving modes - the highest values were $8.68 \%$ of the distance and $3.36 \%$ of the drive time for HV driving.

The energy flow analysis in the hybrid drive system indicates the following:

- the energy balance for each drive cycle was positive battery energy increased; similarly, the battery SOC value increased in the entire test,

- about $70 \%$ of the battery energy changes (charging and discharging) took place in the urban driving phase; similar relation could be observed for energy recovery; the remaining driving phases had little impact on the vehicle energy balance; hence these results indicate the high potential of using such a drive in urban conditions,

- high vehicle speeds force the system to operate in hybrid mode, during which the engine operation also charging the high voltage battery.

Analysis of the electric driving mode usage indicates the following:

- the EV mode share was about $32 \%$ of the total test distance and about $36 \%$ of the test duration,

- the highest electric mode share values were recorded during urban (about $50 \%$ ) and rural (about $32 \%$ on average) drive sections; whereas the smallest share of the 
EV mode was observed on the highway section around $13 \%$,

- the lowest EV mode share was recorded for vehicle acceleration - at about $3 \%-97 \%$ of the distance covered when accelerating, where the vehicle accelerates using the internal combustion engine (or hybrid drive); the overall electric drive mode share (excluding acceleration and braking) was around $10 \%$.
The research presented in this paper was performed within the statutory work, project no. 05/52/DSPB/0279.

\section{Acknowledgement}

The authors would like to thank Mr Andrzej Szalek representatives at Toyota Motor Poland Company Ltd. in Warsaw, Poland for their provision of an vehicle for testing.

\section{Nomenclature}

\begin{tabular}{|c|c|c|c|}
\hline $\mathrm{E}$ & energy & OBD & on-board diagnostic \\
\hline $\mathrm{ECO}$ & eco mode & $\mathrm{RDE}$ & real driving emissions \\
\hline $\mathrm{EV}$ & electric vehicle & SOC & state of charge \\
\hline $\mathrm{HEV}$ & hybrid electric vehicle & SPORT & sport mode \\
\hline I & current & $\mathrm{t}$ & time \\
\hline IB & battery current & $\mathrm{U}$ & voltage \\
\hline Li-Ion & lithium-ion battery & $\mathrm{V}$ & velocity \\
\hline MG1 & motor/generator 1 & & \\
\hline MG2 & motor/generator 2 & Indexes & \\
\hline $\mathrm{M}_{\mathrm{o}}$ & motor torque & $\mathrm{ch}$ & charging \\
\hline $\mathrm{M}_{\mathrm{reg}}$ & braking torque & dis & discharge \\
\hline MSHS & Multi Stage Hybrid System & reg & regeneration \\
\hline $\begin{array}{l}\text { MSSD } \\
n\end{array}$ & $\begin{array}{l}\text { Multi Stage Shift Device } \\
\text { engine speed }\end{array}$ & veh & vehicle \\
\hline
\end{tabular}

\section{Bibliography}

[1] ANDERSSON, J. Particle Number (PN) measurement experiences from 2016 AECC GDI GPF project. AECC Seminar on real-driving emissions of particles. Brussels, 2016.

[2] CIEŚLIK, W., PIELECHA, I., SZAŁEK, A. Assessment of parameters of the hybrid drive system in vehicles in urban traffic conditions. Combustion Engines. 2015, 161(2), 14-27.

[3] Commission Regulation (EU) 2016/646 of 20 April 2016 amending Regulation (EC) No 692/2008 as regards emissions from light passenger and commercial vehicles (Euro 6), Verifying Real Driving Emissions, Official J. European Union, L 109, 2016.

[4] KATO, S., ANDO, I., OHSHIMA, K. et al. Development of Multi Stage Hybrid System for New Lexus Coupe. SAE Technical Paper, 2017-01-1173.DOI:10.4271/2017-01-1173.

[5] KUMAZAKI, K., MATSUBARA, T., KOBAYASHI, N. et al. Development of shift control system for Multi Stage Hybrid Transmission. SAE Technical Paper 2017-01-1150, 2017.DOI:10.4271/2017-01-1150.

[6] Lexus Experience Amazing, newsroom.lexus.eu (accessed 17.10.2018)

[7] Lexus Tech: Inside the Multi-Stage Hybrid System, 14.12.2017. lexusenthusiast.com (accessed 03.09.2018).

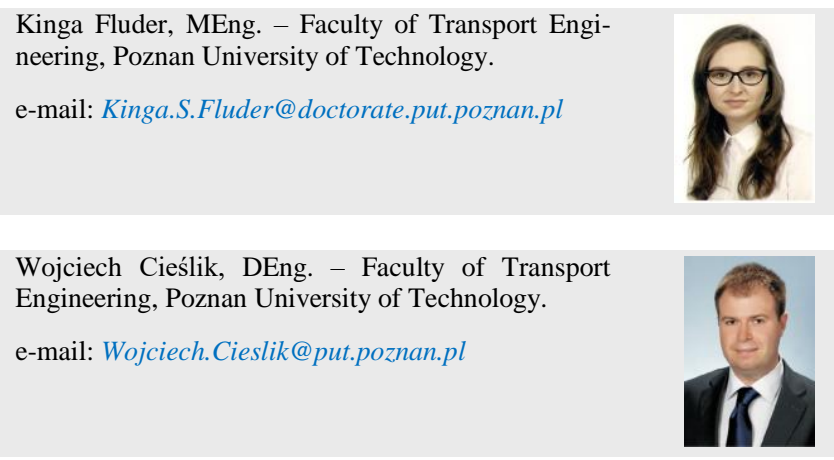

[8] MAIWALD, O., BRUCK, R., ROHRER, S. et al. Optimised diesel combustion and SCR exhaust aftertreatment combined with a $48 \mathrm{~V}$ system for lowest emissions and fuel consumption in RDE. Aachen Colloquium, 2016.

[9] MERKISZ, J., PIELECHA, I. Mechanical systems for hybrid vehicles. 2015, Publishing House Poznan University of Technology.

[10] OKUDA, K., YASUDA, Y., ADACHI, M. et al. Development of Multi Stage Hybrid Transmission. SAE Int. J. Alt. Power. 2017, 6(1). DOI:10.4271/2017-01-1156.

[11] OSHIMA, K., KATO, S. New Multi Stage Hybrid System for the LC500h with innovative drivability of the THSII. 39. Internationales Wiener Motorensymposium. 2018.

[12] PIELECHA, J., JASIŃSKI, R., MAGDZIAK, A. Practicability of passenger vehicle driving emission tests according to new European Union procedures. MATEC Web Conferences 118, 00021, 2017.

[13] SCHARF, J., OGRZEWALLA, J., WOLFF, K. et al. Gasoline engines for hybrid powertrains - high tech or low cost? $38^{\text {th }}$ Internationales Wiener Motorensymposium. 2017.

[14] Toyota Motor Europe, toyota-tech.eu (accessed 10.10.2018).

Prof. Ireneusz Pielecha, DSc., DEng. - Faculty of Transport Engineering, Poznan University of Technology.

e-mail: Ireneusz.Pielecha@put.poznan.pl 